\title{
OmpU as a biomarker for rapid discrimination between toxigenic and epidemic Vibrio cholerae 01/0139 and non-epidemic Vibrio cholerae in a modified MALDI-TOF MS assay
}

Armand Paauw ${ }^{1 *}$, Hein Trip ${ }^{1}$, Marcin Niemcewicz², Ricela Sellek ${ }^{3,4}$, Jonathan ME Heng ${ }^{1}$, Roos H Mars-Groenendijk1, Ad L de Jong ${ }^{1}$, Joanna A Majchrzykiewicz-Koehorst ${ }^{1}$, Jaran S Olsen ${ }^{5}$ and Evgeni Tsivtsivadze ${ }^{1}$

\begin{abstract}
Background: Cholera is an acute diarrheal disease caused by Vibrio cholerae. Outbreaks are caused by a genetically homogenous group of strains from serogroup $\mathrm{O} 1$ or $\mathrm{O} 139$ that are able to produce the cholera toxin. Rapid detection and identification of these epidemic strains is essential for an effective response to cholera outbreaks.

Results: The use of ferulic acid as a matrix in a new MALDI-TOF MS assay increased the measurable mass range of existing MALDI-TOF MS protocols for bacterial identification. The assay enabled rapid discrimination between epidemic $V$. cholerae $\mathrm{O} 1 / 0139$ strains and other less pathogenic $V$. cholerae strains. $\mathrm{OmpU}$, an outer membrane protein whose amino acid sequence is highly conserved among epidemic strains of $V$. cholerae, appeared as a discriminatory marker in the novel MALDI-TOF MS assay.

Conclusions: The extended mass range of MALDI-TOF MS measurements obtained by using ferulic acid improved the screening for biomarkers in complex protein mixtures. Differences in the mass of abundant homologous proteins due to variation in amino acid sequences can rapidly be examined in multiple samples. Here, a rapid MALDI-TOF MS assay was developed that could discriminate between epidemic O1/O139 strains and other less pathogenic $V$. cholerae strains based on differences in mass of the OmpU protein. It appeared that the amino acid sequence of OmpU from epidemic $V$. cholerae $01 / 0139$ strains is unique and highly conserved.
\end{abstract}

\section{Background}

Cholera is an acute diarrheal disease caused by Vibrio cholerae that can be lethal within hours if left untreated. In 2011, a total of 589,854 cases were registered from 58 countries, including 7,816 deaths [1]. The severity, duration, and frequency of cholera epidemics appear to be increasing [2], indicating that cholera is a severe public health problem. In addition, $V$. cholerae is considered a category $\mathrm{B}$ bioterrorism agent by the CDC [3]. Infection usually occurs by consumption of contaminated water, the natural habitat of $V$. cholerae, or contaminated food. Within the V. cholerae species, over 200 serogroups have been identified but only serogroup O1 and O139 strains

\footnotetext{
* Correspondence: armand.paauw@TNO.nl

'Department of CBRN Protection, TNO, P.O. Box 45, Rijswijk 2280 AA, The Netherlands

Full list of author information is available at the end of the article
}

that are able to produce cholera enterotoxin $(\mathrm{CT})$ and toxin-coregulated pilus (TCP) can cause epidemics. The toxigenicity of a $V$. cholerae strain depends on its ability to produce the $C T$, encoded by the $\operatorname{ctx} A B$ genes, and TCP, encoded by the Vibrio pathogenicity island (VPI) [4]. However, these virulence factors are also described in non-O1/O139 $V$. cholerae isolates without causing an epidemic threat [5]. Next, occasionally, other strains of $V$. cholerae may cause diarrhea, but they do not have epidemic potential [6]. Rapid detection and identification of threatening microorganisms is essential for an effective response to an infectious disease outbreak. Therefore, rapid discrimination between epidemic $V$. cholerae O1/O139 strains and other $V$. cholerae strains is crucial. Matrix-assisted laser desorption/ionization time-of-flight mass spectrometry (MALDI-TOF MS) is increasingly used for quick identification of bacteria and possesses advantages 
over conventional techniques in that it is fast, accurate, cheap and suitable for high-throughput identification [7-10]. The discriminatory power of MALDI-TOF MS in analysis of whole bacterial cell lysates overlaid with $\alpha$ cyano-4-hydroxycinnamic acid as a matrix is usually sufficient to identify bacteria to the species level but may also be used to differentiate between strains belonging to one species if adequate protein extraction procedures are performed [11-15]. The aim of this study was to develop a MALDI-TOF MS assay able to discriminate between toxigenic and epidemic $V$. cholerae O1/O139 strains and other mostly non-O1/O139 isolates. To extend the measurable range of the MALDI-TOF MS and thereby increase the discriminatory power of the MS spectra, ferulic acid was used as a matrix [16,17]. The outer membrane protein OmpU was identified as a suitable biomarker for discriminating between toxigenic and epidemic strains and nonepidemic strains.

\section{Methods}

\section{Bacterial strains}

In total, 48 clinical and environmental isolates of $V$. cholerae and Vibrio mimicus (Table 1) were obtained from Instituto Tecnológico La Marañosa, Spanish Ministry of Defence, San Martín de la Vega, Madrid, Spain, Norwegian Defence Research Establishment, Kjeller, Norway, and Military Institute of Hygiene and Epidemiology, Pulawy, Poland (Table 1) [18-20]. The human isolates were all collected as part of standard patient care. The isolates were collected from different areas of the world. Thirty-three, three, and twelve isolates were serotyped as O1, O139, and non-O1/O139 serogroups, respectively. From the 33 serogroup O1 isolates, 18 were clinical isolates, 10 were environmental isolates, and five isolates were from an unknown source. Two serogroup O139 isolates were clinical isolates and one was of unknown origin. From the isolates not belonging to serogroup $\mathrm{O} 1$ or O139, two isolates were of clinical origin and the 10 remaining isolates were of environmental origin.

\section{Confirmation of strain identification}

Identification of the isolates at species level was confirmed by MALDI-TOF MS using Biotyper 2.0 (Bruker Daltonics $\mathrm{GmbH}$, Bremen, Germany) [11]. Serogroup and serotype were confirmed using the Vibrio cholerae E Agglutinating Sera kit containing specific antisera $\mathrm{O} 1$ polyvalent agglutination serum, Inaba agglutination serum, and Ogawa agglutination serum (Remel Europe Ltd. Darford, Kent, United Kingdom) according to the manufacturer's guidelines.

\section{Genotyping of isolates with multilocus sequence typing (MLST) analysis}

MLST analysis was performed according to Teh et al. [21]. Internal gene fragments of $d n a E$, lap, $r e c A, g y r B$, and cat were PCR amplified and sequenced. The gmd gene was not included in the analysis due to low discriminatory power [21]. Each sequence variant of a locus was assigned a distinct allele number. In the case that no PCR product could be obtained for a specific allele, the number zero was assigned. The allele profiles were entered into BioNumerics version 6.6 software (Applied-Maths, Belgium) as character values, and the genetic relationship between isolates was constructed using the categorical coefficient and the Minimum Spanning Tree algorithm. Isolates that differed at two or fewer loci were considered genetically closely related, while single locus variants (SLV) were defined as having at least three alleles that were different from all other tested isolates.

Isolates were screened for the presence of the virulence genes $\operatorname{ctx} A B$ and $t c p A$ by PCR [21]. Template DNA was obtained from supernatants of cell suspensions lysed by heating for $10 \mathrm{~min}$ at $95^{\circ} \mathrm{C}$. Amplification of DNA fragments from $d n a E$, lap, $\operatorname{rec} A, \operatorname{gyr} B$, cat, ompU, $\operatorname{tx} A B$, and $t c p A$ was performed with a HotStar Taq MasterMix kit (Qiagen, Westburg b.v., Leusden, The Netherlands). The primers used were previously described by Teh et al. [21]. The ompU genes from 9 isolates (including three epidemic strains (080025/EZ [O1 Ogawa], FFIVC130 [O139], and FFIVC129 [O1 Hikojima]), six environmental isolates (FFIVC114, 080025/FE, 080025/ FI, 080025/FL, 17/110/2006, and 2/110/2006) were amplified using the primers ompU-fw (5'-ACCTATTTCGATT GACGTGGC-3') and ompU-rv (5'-ACATCCACCAAG AAACGTTGC-3'), which anneal approximately 80 bp upand downstream of the ompU open reading frames. The PCR products were bidirectionally sequenced. DNA sequencing was performed by BaseClear B.V. (Leiden, The Netherlands).

\section{Sample preparation for MALDI-TOF MS analysis}

$V$. cholerae isolates were grown for $16 \mathrm{~h}$ at $35^{\circ} \mathrm{C}$ on blood agar plates. Sample preparation for MALDI-TOF MS analysis of whole cell lysates was performed as previously described [11]. Each isolate sample was spotted eight times on the MALDI target. Four spots were overlaid with $0.5 \mu \mathrm{l}$ of $10 \mathrm{mg} / \mathrm{ml} \alpha$-cyano-4-hydroxycinnamic acid (HCCA, Bruker Daltonics) in an acetonitrile/ water solution (1:1) with $2.5 \%$ trifluoroacetic acid (Fluka/ Aldrich, Stenheim, Germany). Four spots were overlaid with $0.5 \mu \mathrm{l}$ of a matrix solution containing $12.5 \mathrm{mg} / \mathrm{ml}$ ferulic acid (Sigma-Aldrich), 17\% formic acid and 33\% acetonitrile (LC-MS grade, Fluka/Aldrich, Stenheim, Germany), hereafter referred to as FA+ $[16,17]$. Spots were dried at room temperature.

\section{Mass spectra acquisition}

The mass spectra were acquired automatically on a Bruker Autoflex III smartbeam instrument (Bruker Daltonics) in 
Table 1 V. cholerae isolates analyzed in this study

\begin{tabular}{|c|c|c|c|c|c|c|c|c|c|c|c|c|c|c|c|c|c|}
\hline \multirow[b]{2}{*}{ Strain no. } & \multirow[b]{2}{*}{ Aliases } & \multirow[b]{2}{*}{ Serogroup } & \multirow[b]{2}{*}{ Serotype } & \multicolumn{3}{|c|}{$\begin{array}{l}\text { Presence (1) or absence (0) } \\
\text { of virulence genes }\end{array}$} & \multirow[b]{2}{*}{ Year } & \multirow[b]{2}{*}{ Host } & \multirow[b]{2}{*}{$\begin{array}{l}\text { Geographic } \\
\text { origin }\end{array}$} & \multirow[b]{2}{*}{$\begin{array}{l}\text { MLST genotype } \\
\text { (GT) }\end{array}$} & \multicolumn{5}{|c|}{$\begin{array}{l}\text { Allelic variants of targeted } \\
\text { genes in MLST }\end{array}$} & \multirow[b]{2}{*}{$\begin{array}{l}\text { MSP } \\
\text { value }^{b}\end{array}$} & \multirow[b]{2}{*}{ Reference $^{c}$} \\
\hline & & & & $c t \times A B$ & $t c p A-R 1$ & $t c p A-R 2$ & & & & & cat & $d n a E$ & gyrB & lap & $\operatorname{rec} A$ & & \\
\hline 080025/EY & Vib12, F 751 & 01 & Ogawa & 1 & 1 & 0 & 1990 & Human & Spain & 1 & 1 & 1 & 1 & 1 & 1 & 2.48 & {$[18,19]$} \\
\hline 080025/EZ & Vib13, F 752 & 01 & Ogawa & 1 & 1 & 0 & 1990 & Human & Spain & 1 & 1 & 1 & 1 & 1 & 1 & 2.17 & {$[18,19]$} \\
\hline 080025/FA & Vib14, F 753 & 01 & Ogawa & 1 & 1 & 0 & 1990 & Human & Spain & 1 & 1 & 1 & 1 & 1 & 1 & 2.46 & {$[18,19]$} \\
\hline 080025/FB & Vib15, F 754 & $\mathrm{O} 1$ & Ogawa & 1 & 1 & 0 & 1990 & Human & Spain & 1 & 1 & 1 & 1 & 1 & 1 & 2.30 & {$[18,19]$} \\
\hline 080025/FC & Vib16, F 755 & 01 & Ogawa & 1 & 1 & 0 & 1990 & Human & Spain & 1 & 1 & 1 & 1 & 1 & 1 & 2.36 & {$[18,19]$} \\
\hline 080025/FD & Vib17, F 756 & 01 & Ogawa & 1 & 1 & 0 & 1990 & Water & Spain & 1 & 1 & 1 & 1 & 1 & 1 & 2.19 & {$[18,19]$} \\
\hline 080025/FE & Vib18, F 758 & 01 & Inaba & 0 & 0 & 0 & 1991 & Water & Spain & 2 & 13 & 0 & 5 & 8 & 12 & 2.38 & {$[18,19]$} \\
\hline 080025/FF & Vib19, F 759 & 01 & Inaba & 0 & 0 & 0 & 1991 & Water & Spain & 2 & 12 & 0 & 5 & 8 & 12 & 2.22 & {$[18,19]$} \\
\hline 080025/FG & Vib20, F 760 & 01 & Inaba & 0 & 0 & 0 & 1991 & Water & Spain & 2 & 12 & 0 & 5 & 8 & 12 & 2.22 & {$[18,19]$} \\
\hline 080025/FH & Vib21, F 761 & 01 & Inaba & 0 & 0 & 0 & 1991 & Prawn & Ecuador & 2 & 12 & 0 & 3 & 9 & 12 & 2.21 & {$[18,19]$} \\
\hline 080025/FI & Vib22, F 763 & 01 & Inaba & 0 & 0 & 0 & 1991 & Prawn & Ecuador & 2 & 13 & 0 & 3 & 9 & 13 & 2.19 & {$[18,19]$} \\
\hline 080025/FJ & Vib23, F 762 & 01 & Inaba & 0 & 0 & 0 & 1991 & Prawn & Ecuador & 2 & 12 & 0 & 3 & 9 & 12 & 2.32 & {$[18,19]$} \\
\hline 080025/FK & Vib24, F 764 & 01 & Inaba & 0 & 0 & 0 & 1991 & Prawn & Ecuador & 2 & 12 & 0 & 3 & 9 & 12 & 2.30 & {$[18,19]$} \\
\hline 080025/FL & Vib25, F 766 & 01 & Ogawa & 0 & 0 & 0 & 1992 & Water & Spain & 3 & 9 & 8 & 11 & 7 & 8 & 2.37 & {$[18,19]$} \\
\hline 080025/FM & Vib26, F 768 & $\mathrm{O} 1$ & Ogawa & 1 & 1 & 0 & 1992 & Human & Spain & 1 & 1 & 1 & 1 & 1 & 1 & 2.15 & {$[18,19]$} \\
\hline 080025/FN & Vib27, F 767 & 01 & Ogawa & 1 & 1 & 0 & 1992 & Human & Spain & 1 & 1 & 1 & 1 & 1 & 1 & 2.47 & {$[18,19]$} \\
\hline 080025/FO & Vib28, F 765 & 01 & Inaba & 0 & 0 & 0 & 1991 & Prawn & Ecuador & 2 & 13 & 0 & 3 & 9 & 12 & 2.25 & {$[18,19]$} \\
\hline 080025/FP & Vib29 & 01 & Ogawa & 1 & 1 & 0 & 1993 & Human & Spain & 1 & 1 & 1 & 1 & 1 & 1 & 2.18 & [18] \\
\hline 080025/FQ & Vib30 & 01 & Ogawa & 1 & 1 & 0 & 1993 & Human & Spain & 1 & 1 & 1 & 1 & 1 & 1 & 2.40 & [18] \\
\hline 080025/FS & Vib32 & 01 & Ogawa & 0 & 0 & 0 & 1994 & Human & Spain & 3 & 9 & 0 & 11 & 7 & 8 & 2.17 & [18] \\
\hline 080025/FT & Vib33 & 01 & Ogawa & 1 & 1 & 0 & 1994 & Human & Spain & 1 & 1 & 1 & 1 & 1 & 1 & 2.22 & [18] \\
\hline 080025/FU & Vib34 & 01 & Ogawa & 1 & 1 & 0 & 1994 & Human & Spain & 1 & 1 & 1 & 1 & 1 & 1 & 2.37 & {$[18]$} \\
\hline 080025/FV & Vib35 & 01 & Ogawa & 1 & 1 & 0 & 1994 & Human & Spain & 1 & 1 & 1 & 1 & 1 & 1 & 2.50 & [18] \\
\hline 080025/FW & Vib36 & 01 & Ogawa & 1 & 1 & 0 & 1995 & Human & Spain & 1 & 1 & 1 & 1 & 1 & 1 & 2.37 & [18] \\
\hline 080025/FX & Vib37 & 01 & Ogawa & 1 & 1 & 0 & 1995 & Human & Spain & 1 & 1 & 1 & 1 & 1 & 1 & 2.48 & [18] \\
\hline 080025/GD & Vib43 & 01 & Ogawa & 1 & 1 & 0 & & unknown & unknown & 1 & 2 & 1 & 1 & 1 & 2 & 2.37 & [18] \\
\hline 080025/GE & Vib44 & 01 & Inaba & 0 & 0 & 1 & & unknown & unknown & 3 & 9 & 0 & 11 & 7 & 0 & 2.45 & [18] \\
\hline FFIVC057 & $2 / 23$ & 01 & Ogawa & 1 & 1 & 0 & 1994 & Epidemic & Italy & 1 & 1 & 1 & 1 & 1 & 1 & 2.50 & [20] \\
\hline FFIVC058 & $2 / 26$ & 01 & Ogawa & 1 & 1 & 0 & 1994 & Epidemic & Italy & 1 & 1 & 1 & 1 & 1 & 1 & 2.46 & [20] \\
\hline FFIVC065 & $2 / 70$ & 01 & Ogawa & 1 & 1 & 0 & 1994 & Epidemic & Albania & 1 & 1 & 1 & 1 & 1 & 1 & 2.51 & [20] \\
\hline
\end{tabular}


Table $1 \mathrm{~V}$. cholerae isolates analyzed in this study (Continued)

\begin{tabular}{|c|c|c|c|c|c|c|c|c|c|c|c|c|c|c|c|c|c|}
\hline FFIVC129 & ATCC 33655 & $\mathrm{O} 1$ & Hikojima & 1 & 0 & 1 & 1979 & unknown & unknown & 1 & 2 & 1 & 1 & 1 & 2 & 1.99 & {$[20]$} \\
\hline FFIVC016 & & 01 & Ogawa & 1 & 0 & 1 & & unknown & unknown & 1 & 2 & 1 & 1 & 1 & 2 & 2.39 & [20] \\
\hline $14 / 2002 / S$ & & 01 & Unknown & 1 & 1 & 0 & & unknown & unknown & 1 & 1 & 1 & 1 & 0 & 1 & 2.42 & {$[20]$} \\
\hline FFIVC130 & ATCC51394 & 0139 & & 1 & 1 & 0 & 1995 & Human & India & 1 & 1 & 1 & 1 & 1 & 1 & 2.37 & [20] \\
\hline FFIVC131 & CDC2412-93 & 0139 & & 1 & 1 & 0 & 1995 & Human & USA & 1 & 1 & 1 & 1 & 1 & 1 & 2.43 & [20] \\
\hline FFIVC133 & & 0139 & & 1 & 1 & 0 & 2003 & unknown & unknown & 1 & 1 & 1 & 1 & 1 & 1 & 2.49 & [20] \\
\hline 080025/FR & Vib31 & 0141 & & 1 & 1 & 1 & 1993 & Human & Spain & singleton & 8 & 7 & 3 & 2 & 9 & 2.24 & [18] \\
\hline FFIVC050 & & non 01/0139 & & 0 & 0 & 0 & & Mussels & Norway & singleton & 8 & 9 & 9 & 11 & 5 & 2.28 & [20] \\
\hline FFIVC084 & & non 01/0139 & & 0 & 0 & 0 & 2003 & Mussels & Norway & singleton & 4 & 2 & 4 & 3 & 3 & 2.45 & [20] \\
\hline FFIVC114 & & non 01/0139 & & 0 & 0 & 0 & 2004 & Water & Norway & 4 & 6 & 1 & 6 & 6 & 6 & 2.29 & [20] \\
\hline FFIVC115 & & non 01/0139 & & 0 & 0 & 0 & 2004 & Water & Norway & 4 & 6 & 1 & 6 & 6 & 6 & 2.39 & [20] \\
\hline FFIVC137 & & non 01/0139 & & 0 & 0 & 0 & & Human & Norway & singleton & 7 & 5 & 8 & 10 & 4 & 2.41 & {$[20]$} \\
\hline $2 / 110 / 2006$ & & non 01/0139 & & 0 & 0 & 0 & 1998 & Water & Poland & 5 & 10 & 4 & 2 & 12 & 4 & 2.25 & [18] \\
\hline $3 / 110 / 2006$ & & non 01/0139 & & 0 & 0 & 0 & 1998 & Water & Poland & 5 & 10 & 4 & 2 & 12 & 4 & 2.42 & [18] \\
\hline 4/110/2006 & & non 01/0139 & & 0 & 0 & 0 & 2004 & Water & Poland & singleton & 11 & 0 & 13 & 0 & 11 & 2.38 & [18] \\
\hline 14/110/2006 & & non 01/0139 & & 0 & 0 & 0 & 1998 & Water & Poland & singleton & 5 & 3 & 10 & 4 & 7 & 2.37 & [18] \\
\hline 17/110/2006 & & non 01/0139 & & 0 & 0 & 0 & 1998 & Water & Poland & 6 & 3 & 6 & 7 & 5 & 10 & 2.47 & [18] \\
\hline 22/110/2006 & & non 01/0139 & & 0 & 0 & 0 & 2004 & Water & Poland & 6 & 3 & 6 & 7 & 5 & 10 & 2.26 & [18] \\
\hline 070256/J & $\begin{array}{l}\text { V. mimicus } \\
\text { ATCC } 33655\end{array}$ & - & & 1 & 0 & 0 & & & & 10 & 14 & 10 & 12 & 1 & 14 & 1.71 & [18] \\
\hline
\end{tabular}

${ }^{a}$ " 0 " means no PCR product was obtained.

${ }^{\mathrm{b}} \mathrm{MSP}$ value: highest logarithmic value of the four generated MS-spectra score value compared to Biotyper reference library.

'Reference(s), in which the isolate is described previously. 
linear mode. Spots overlaid with HCCA matrix were analyzed using the following parameters: 50\% laser intensity, positive polarity, $350 \mathrm{~ns}$ PIE delay, acceleration voltage of $20 \mathrm{kV}$ (source 1) and $18.7 \mathrm{kV}$ (source 2), lens voltage of $8 \mathrm{kV}$, linear detector voltage of $1.522 \mathrm{kV}$, and $500 \mathrm{Da}$ detector gating. Composite mass spectra were generated from 10 different positions per spot using, in total, 2,000 laser shots at each spot generated by a $200-\mathrm{Hz}$ smartbeam laser $(355 \mathrm{~nm})$. The mass spectra were recorded in a mass/ charge $(m / z)$ range of $2,000-20,000$. The parameters used for analysis of the spots overlaid with the FA+ matrix were: $80 \%$ laser intensity, positive polarity, 350 ns PIE delay, acceleration voltage of $20 \mathrm{kV}$ (source 1) and $18.7 \mathrm{kV}$ (source 2), lens voltage of $2.8 \mathrm{kV}$, linear detector voltage of $1.522 \mathrm{kV}$, and $4000 \mathrm{Da}$ detector gating. Composite mass spectra were generated from 10 different positions per spot using, in total, 2,000 laser shots at each spot generated by a $200-\mathrm{Hz}$ smartbeam laser (355 nm). The mass spectra were recorded in a $\mathrm{m} / z$ range of 4,000 80,000 . The instrument was externally calibrated with a bacterial test standard (BTS, Bruker Daltonics) when analyzing HCCA-overlaid spots or peptide calibration standard II (Bruker Daltonics) when analyzing spots overlaid with FA+. To evaluate the reproducibility of the newly developed method, the entire test was repeated on a separate day.

\section{Data analysis MS spectra}

The MS spectra obtained from the spots overlaid with the HCCA matrix were analyzed using MALDI Biotyper 2.0 software and Bruker's security relevant library (Bruker Daltonics). These libraries together contain 83 reference spectra (MSPs) from various Vibrio species, including three $V$. cholerae strains and one $V$. mimicus strain. For each measurement, a logarithmic score value was determined by calculating the proportion of matching peaks and peak intensities between the test spectrum and the reference spectra of the database [11,13]. Identification at species level was based on the highest of the four logarithmic values [11]. All MS spectra obtained from spots overlaid with the FA+ matrix were analyzed using Matlab software (version R2011b). The spectra were first converted into the MZXML format using the Bruker Daltonics supplied software (CompassXport) and subsequently converted to the Matlab binary format using mzxml read procedure. Further processing was performed using the Matlab Bioinformatics toolbox (Version 4.0) routines such as resampling (msresample - mass range 10,000 to $50,000 \mathrm{Da}$ and resampling to 5,000 data points), baseline subtraction (msbackadj), alignment on a peak mass of 11974 (msalign), which was present in the MS spectra of all $V$. cholerae isolates, normalization (msnorm) and visualization of spectra in a heat map. Peaks were automatically selected using standard peak selection algorithm (mspeaks - HeightFilter $=2$ ). The highest peak in the region of $32.5-37.5 \mathrm{kDa}$ per isolate was automatically identified.

\section{Protein identification by SDS-PAGE coupled to LC-MS/MS}

Viable cells of the $V$. cholerae isolates FFIVC129, FFIVC130, 080025/EZ, 080025/FC, 080025/FE, 080025/FI, FFIVC137 and 17/110/2006 were resuspended in $50 \mu \mathrm{l}$ phosphate-buffered saline and mixed with $50 \mu \mathrm{l}$ Laemmli $2 \mathrm{x}$ sample buffer (Bio-Rad). Samples were incubated at $100^{\circ} \mathrm{C}$ for 10 minutes and analyzed by standard SDSPAGE using a $12 \%$ polyacrylamide gel and Coomassie Brilliant Blue staining [22]. The most prominent protein bands in the mass range of 34 to $38 \mathrm{kDa}$ were excised from the gel and subjected to in-gel trypsin digestion. Gel pieces were washed with pure water, destained with three rounds of washing in a mixture of $70 \% 25 \mathrm{mM}$ $\mathrm{NH}_{4} \mathrm{HCO}_{3} / 30 \%$ acetonitrile (ACN) and dehydrated by 10 minutes of incubation in $100 \% \mathrm{ACN}$. After removal of $\mathrm{ACN}$, gel pieces were incubated in $100 \mathrm{mM} \mathrm{NH} \mathrm{NCO}_{3} /$ $10 \mathrm{mM}$ dithiothreitol for $30 \mathrm{~min}$ at $56^{\circ} \mathrm{C}$ followed by addition of iodoacetamide to a final concentration of $55 \mathrm{mM}$ and $30 \mathrm{~min}$ of incubation at room temperature. Gel pieces were washed in $25 \mathrm{mM} \mathrm{NH}_{4} \mathrm{HCO}_{3}$, dehydrated by incubation in $100 \% \mathrm{ACN}$, placed in $50 \mu \mathrm{l}$ $100 \mathrm{mM} \mathrm{NH} \mathrm{HCO}_{3}$ containing $10 \mathrm{ng} / \mathrm{ml}$ trypsin (from bovine pancreas, Sigma-Aldrich) and incubated overnight at $37^{\circ} \mathrm{C}$. The remaining liquid was transferred to a clean tube, and peptides were extracted from the gel pieces by two rounds of 5 minute incubation in $50 \mu \mathrm{l} 60 \% \mathrm{ACN}$, $1 \%$ trifluoroacetic acid in an ultrasonic bath $(37 \mathrm{kHz})$. The combined fractions were dried in a SpeedVac, and the pellets were resuspended in $30 \mu \mathrm{H}_{2} \mathrm{O}$. The samples were analyzed by liquid chromatography-tandem mass spectrometry using an Ultimate 3000 RSLnano LC system (Thermo Scientific, Sunnyvale, CA) coupled to an HCTultra ion trap mass spectrometer (Bruker Daltonics). Samples were injected onto an Acclaim $\mathrm{C}_{18}$ PepMap100 trapping column (Thermo Scientific) and washed with $100 \%$ buffer A (3\% ACN in $0.1 \%$ formic acid) at $5 \mu \mathrm{l} / \mathrm{min}$ for $6 \mathrm{~min}$. Peptides were separated on an Acclaim $\mathrm{C}_{18}$ PepMap RSLC column at a constant flow rate of $300 \mathrm{nl} / \mathrm{min}$. An elution gradient of 3 to $40 \%$ buffer B (95\% ACN in $0.1 \%$ formic acid) was applied over $48 \mathrm{~min}$ followed by an increase to $65 \% \mathrm{~B}$ in $10 \mathrm{~min}$. The nanoflow LC was coupled to the mass spectrometer using a nano-electrospray ionization source. Eluting peptides were analyzed using the data-dependent MS/MS mode over a $300-1500 \mathrm{~m} / \mathrm{z}$ range. The five most abundant ions in an MS spectrum were selected for MS/MS analysis by collision-induced dissociation using helium as collision gas. Peak lists were generated using DataAnalysis 4.0 software (Bruker Daltonics) and exported as Mascot Generic files. These files were searched against the NCBI database 
with $V$. cholerae as taxonomy using the Mascot (version 2.2.1) search algorithm (Matrix Science, London, UK). Trypsin was selected as the enzyme for digestion and up to one missed cleavage site was allowed. Carbamidomethyl cysteine was selected as a fixed modification, and oxidation of methionine was selected as a variable modification.

\section{Results}

\section{Strain identification}

Forty-eight isolates acquired from different strain collections (Table 1) and previously identified as $V$. cholerae were analyzed using MALDI-TOF MS and Biotyper 2.0 software (Bruker Daltonics). All strains were identified as $V$. cholerae with matching scores of 1.99 to 2.51 following the highest matching score rule [11]. As a control, one $V$. mimicus isolate was analyzed, which resulted in a matching score value of 1.71, indicating a 'probable genus identification'. In addition, serogroup and serotype designations were confirmed using specific antisera.

\section{MLST analysis}

To determine the genetic relationship among the 48 $V$. cholerae isolates, a MLST analysis was performed. Accession numbers: cat KF421252 - KF421300, dnaE KF421301 - KF421338, gyrB KF421339 - KF421387, lap KF421388 - KF421434, and recA KF421435 - KF421482. The isolates were differentiated into six different genotypes (GT1-6) and six single locus variants (SLVs) (Table 1). The presence of the virulence genes $\operatorname{ct} x A B$ and $t c p A$ was determined by PCR. All isolates of serogroups $\mathrm{O} 1$ or $\mathrm{O} 139$ that contained the $\operatorname{ctx} A B$ and $t c p A$ were highly related (Figure 1 ). Within this group, all $\mathrm{O} 1$ isolates contained the type-specific antigen of the serotype Ogawa with the exception of one isolate that belonged to serotype Hikojima and one isolate of unknown serotype. $V$. cholerae $\mathrm{O} 1$ strains of serotype Hikojima are considered to be rare [23]. Isolates outside the GT1 group were determined to be negative for $\operatorname{ctx} A B$ with the exception of one SLV, an isolate of serogroup O141 that contained $c t x A B$ and $t c p A$. Eight isolates of serogroup O1, serotype Inaba, isolated from water in Spain and from prawns in Ecuador were genetically closely related (GT2). Three other isolates of Spanish origin were genetically related (GT3). Furthermore, three pairs of closely related isolates were identified. Two pairs were isolated from the Bug river in Poland (GT5, GT6), while another pair was isolated in Norway from seawater near Oslo (GT4). Six SLVs from Spain, Norway and Poland were observed.

\section{MALDI-TOF MS analysis}

To obtain spectra of a wider $\mathrm{m} / \mathrm{z}$ range than acquired with HCCA as a matrix, whole cell extracts were analyzed with MALDI-TOF MS using FA+. Spectra were

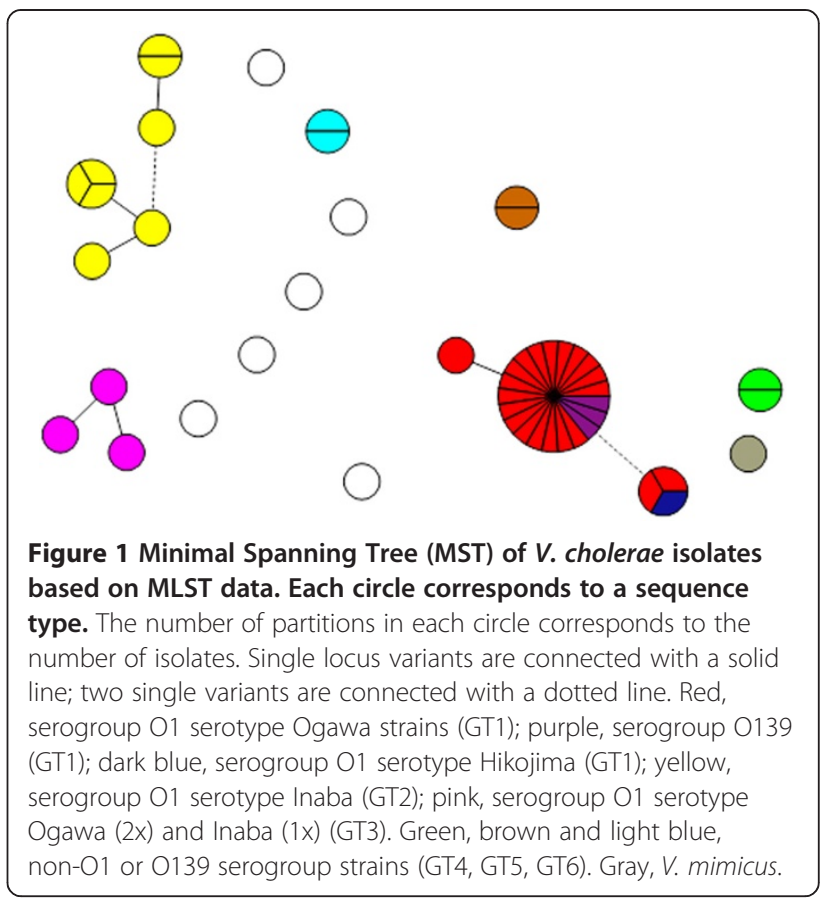

initially recorded in a mass-to-charge range of 4,000 to 80,000 (MZXML data available at http://www.learningmachines.com/). As no significant peaks were visible above an $m / z$ value of 50,000 , spectra were recorded up to $m / z=50,000$ in following experiments (Figure 2). After the datasets were normalized, the baseline was subtracted, and data were aligned and normalized, a heat map was generated to visualize differences between the MS spectra (Figure 3). A simple algorithmic peak search procedure allowed us to identify a prevalent peak near an $m / z$ value of 35,000 that appeared to be discriminatory among the different genotypes (Figure 3 ). In the spectra of all epidemic isolates of serogroups $\mathrm{O} 1$ and O139 (GT1), this peak corresponded to an average mass of $34,750 \mathrm{Da}$ with a standard deviation of $22 \mathrm{Da}$ except for the O1 serotype Hikojima strain $(35,424 \mathrm{Da})$. In the spectra of the other isolates, the corresponding peak differed at least $70 \mathrm{Da}$ from that of GT1 (Figures 3 and 4). The peaks that were closest to the peak mass of the GT1 spectra were those measured in the spectra of GT2, the non-epidemic $V$. cholerae $\mathrm{O} 1$ Inaba isolates related to a Spanish outbreak, which were $34,670+/-20$ Da.

To test the reproducibility of the observed differences in the discriminatory peak masses, the experiment was repeated in a different manner in which isolates were randomly distributed into separate sets. The results for GT1 and GT2 are summarized in Table 2. The mean peak masses of the specific marker in the GT1 and GT2 isolates were $34,565+/-31 \mathrm{Da}$ and $34,495+/-30 \mathrm{Da}$, corresponding to mean mass shifts of -185 and $-175 \mathrm{Da}$, respectively, compared to the first experiment. This shows 

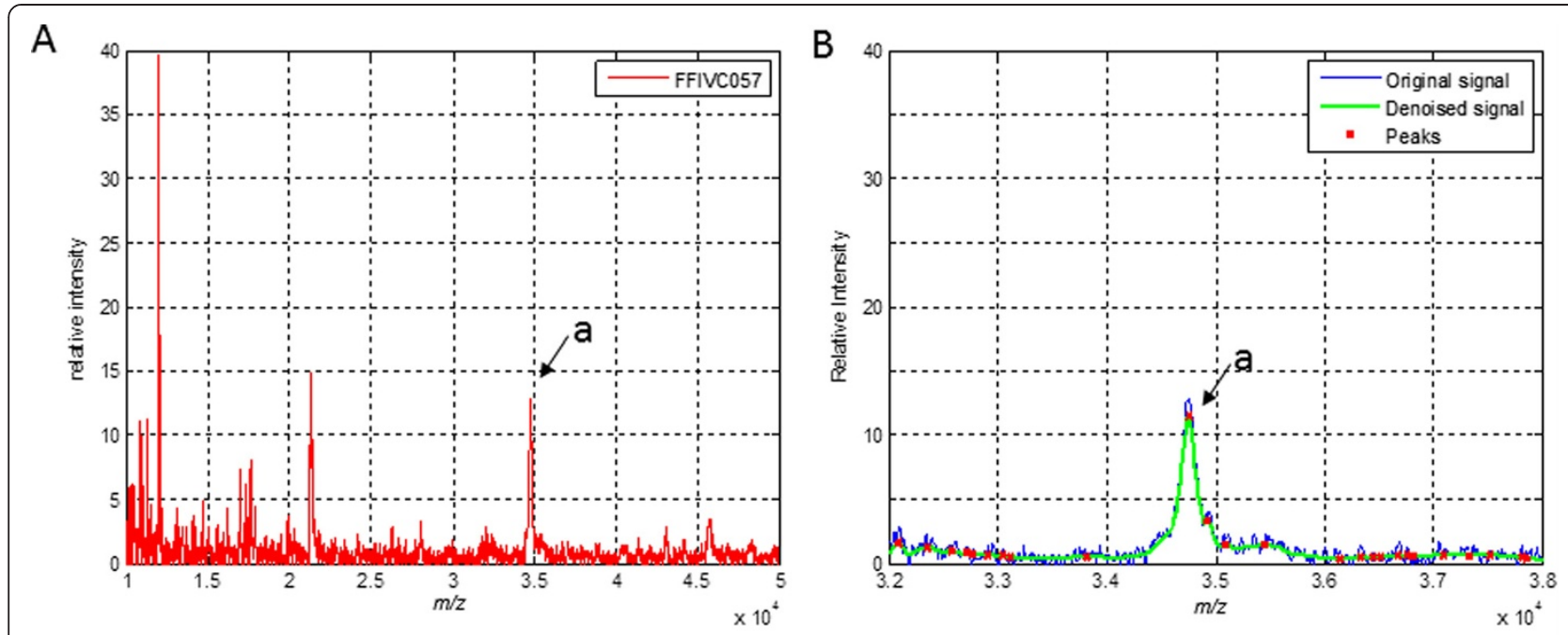

C

D
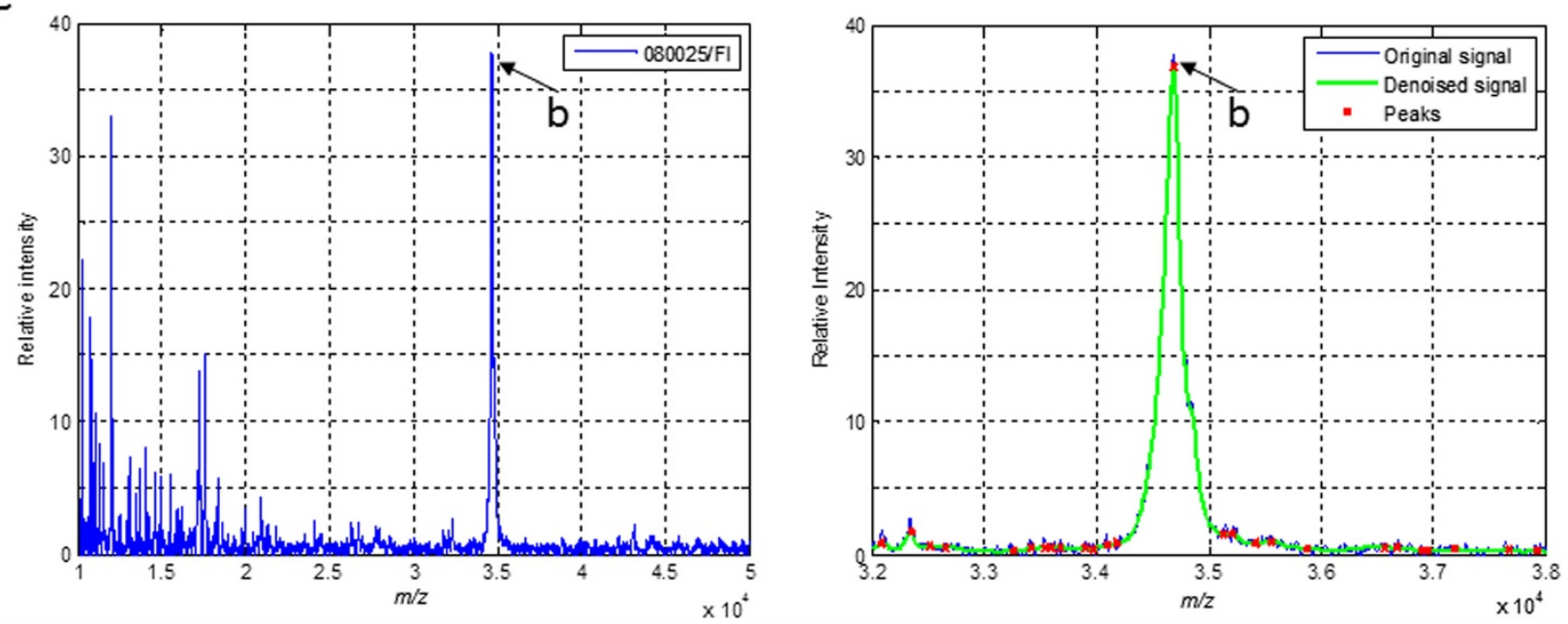

Figure 2 MALDI-TOF MS analysis of whole cell lysates of $\boldsymbol{V}$. cholerae isolates. $\mathbf{A}$ and $\mathbf{B}$, examples of normalized MS spectra of a toxigenic and epidemic serogroup $\mathrm{O} 1$ isolate (A) and a non-toxigenic isolate (B). $\mathbf{C}$ and $\mathbf{D}$, close-ups of selected MS-peak of Figure $\mathbf{A}$ and $\mathbf{B}$, respectively. a, $\mathrm{m} / \mathrm{z}=34,750 \mathrm{Da}, \mathrm{b} \mathrm{m} / \mathrm{z}=34,690 \mathrm{Da}$.

that in the $\mathrm{m} / \mathrm{z}$ range near 35,000 , the measured peak masses can deviate between separate experiments but that differences between different samples are relatively constant. By including an internal control of known mass, spectra can be calibrated. Reproducibility was further supported by the median of the GT1 and GT2 measurements, which were maximally $5 \mathrm{Da}$ different from the mean, indicating a Gaussian distribution of the measurements.

\section{Identification of discriminatory peak as OmpU}

One peak in the MS spectra representing the most abundant protein in a mass range of 30 to $40 \mathrm{kDa}$ in $V$. cholerae cells grown overnight on rich medium agar plates was suggested to be a biomarker to differentiate between various $V$. cholerae strains. To identify this protein, whole cell lysates were analyzed by SDS-PAGE
(Figure 5). Protein extracts from eight isolates of four different genotypes: GT1, 2, 6 and a SLV, were prepared from the same colony material that was used for MS analysis. One prominent band in the mass range of $32-$ $37 \mathrm{kDa}$ was present in the extracts of each of the isolates except for isolate FFIVC129, the 'Hikojima strain', which had two equally strong bands differing approximately $2 \mathrm{kDa}$ in apparent mass. Differences in apparent masses in the SDS-PAGE analysis correlated with the differences of the peak masses in the MS spectra. The protein bands were excised, trypsin digested and analyzed by LC-MS/ MS for identification. Of each band, the vast majority of peptides was identified as derived from OmpU homologs, except for the upper band of the Hikojima strain, which was identified as OmpT (Mascot 2.2.1 analysis). To confirm the correlation of the mass differences of 


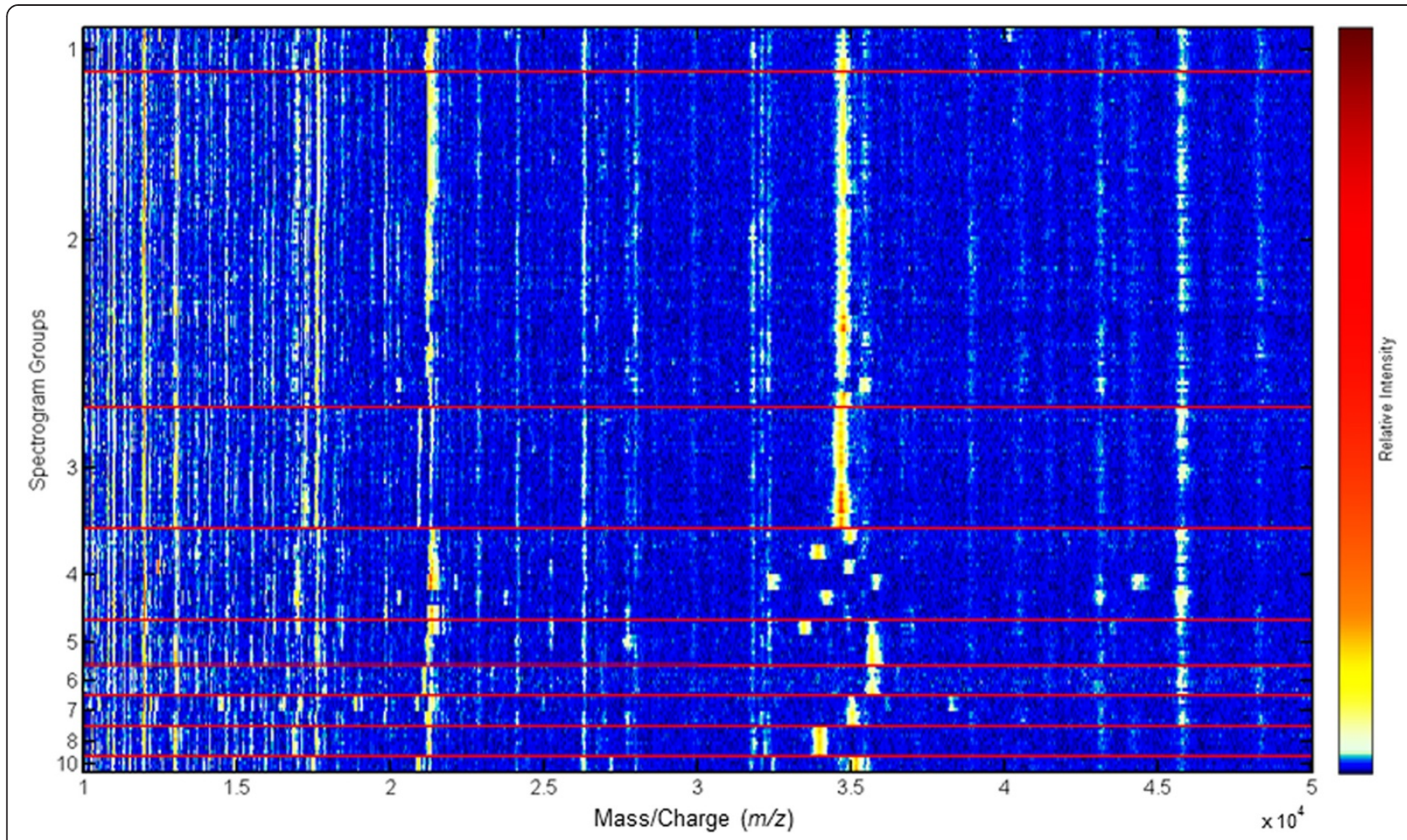

Figure 3 Heat map analysis of MS spectra of $\mathbf{4 8} \mathbf{V}$. cholerae isolates and one $\boldsymbol{V}$. mimicus strain. Each isolate is represented by four spectra (horizontal lanes) obtained from four spots on the MALDI target. The color indicates the peak intensities according to the color scale (left bar). The spectra were divided into spectrogram groups (separated by red horizontal lines): 1, V. cholerae serogroup O139 (GT1); 2, V. cholerae serogroup O1 serotype Hikojima and Ogawa strains (GT1); 3, serogroup O1 serotype Inaba (GT2); 4, SLVs; 5, serogroup O1 serotype Ogawa (2x) and Inaba (1x) (GT3); 6 and 7, two pairs isolated from the Bug river in Poland (GT 4, GT5); 8, pair isolated in Norway (GT6); 10, V. mimicus.

the OmpU homologs with the peak mass differences, the ompU genes of 16 isolates were amplified and sequenced. (Accession numbers: KF434513 - KF434521 and KJ699296 - KJ699302). The theoretical masses of the mature OmpU homologs with omission of the signal peptide correlated with the observed peak masses of the MS spectra (less than $0.41 \%$ difference, Table 3 ) but not well enough to identify an epidemic isolate on basis of the measured peak mass alone. However, the theoretical mass differences between the isolates were consistent with the differences in the MS spectra within one experiment. The amino acid sequences of OmpU proteins from the epidemic $V$. cholerae O1 Ogawa and O139 isolates (080025/EZ and FFIVC130, respectively) were identical to the sequence of the OmpU protein from the epidemic type strain $V$. cholerae O1 El Tor Inaba N16961 (ATCC 39315) (Additional file 1: Figure S1). The OmpU protein from the $V$. cholerae $\mathrm{O} 1$ serotype Hikojima (isolate FFIVC129) differed at three positions (E290K, V324A, G325S) causing a mass difference of only one Dalton (OmpU N16961; 34,656 and OmpU FFIVC120; $34,657 \mathrm{Da})$. The OmpU proteins from the other tested strains deviated more from this sequence (Table 3). The OmpU proteins that were closest in mass were from the non-toxigenic outbreak isolates 080025/FE and 080025/FI (GT2), which differed at 9 positions, resulting in a $72 \mathrm{Da}$ lower mass. The resolution of the MALDI-TOF MS spectra was sufficient to make this distinction (Table 3).

\section{OmpU is conserved among epidemic $V$. cholerae strains}

Using BLASTp, the amino acid sequence of mature OmpU protein of $V$. cholerae N16961, which was used as a reference, was screened against the NCBI protein database (Table 4). At the time of preparation of this article, $181 \mathrm{~V}$. cholerae OmpU homologs were present in the NCBI database. Ninety-six OmpUs were identical to the reference OmpU (from strain N16961) and these were all present in isolates of serogroup O1 or O139 that contain $\operatorname{ctx} A B$ and $t c p A$. One exception to this was a $V$. cholerae isolate of serotype O37 (strain V52), which was isolated during an outbreak in Sudan in 1968 (Table 4). This strain was shown to form a highly uniform clone together with $V$. cholerae $\mathrm{O} 1$ and $\mathrm{O} 139$ [24]. Two strains differed at one position from the reference OmpU. For one of these homologs, no strain information was provided. The OmpU of this isolate was $34 \mathrm{Da}$ lower in mass compared to the reference OmpU. From the other isolate, CP1038(11), a V. cholerae O1 containing 


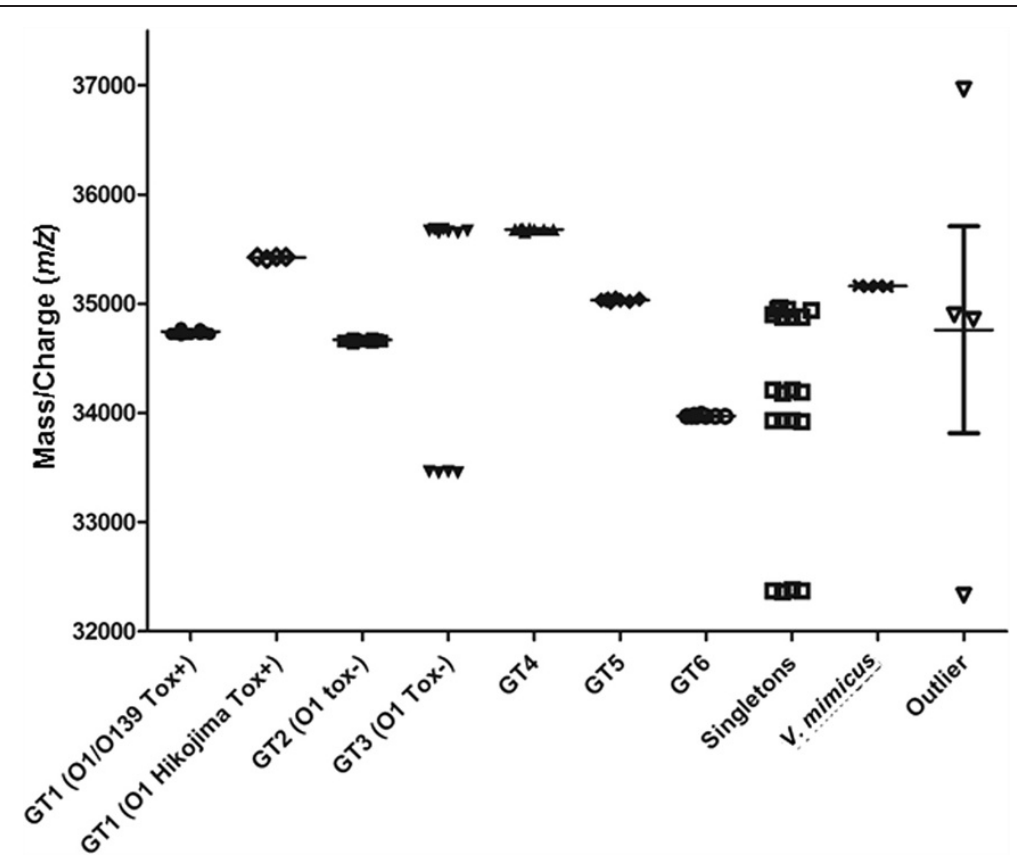

Figure 4 Distribution of the highest-peak positions in the $\mathbf{3 2}$ to $\mathbf{3 8} \mathrm{kDa}$ range grouped per genotype (GT). Each isolate is represented by four peak positions. GT1 (O1/O139 Tox+) comprises 96 peak positions of 24 isolates; GT1 (O1 Hikojima Tox+) comprises 4 peak positions of 1 isolate; GT2 (O1, Tox-) 32 peak positions of 8 isolates; GT3 (O1 Tox-) shows 12 peak positions of 3 isolates with the same genotype but different serotypes. GT4, GT5 and GT6 each comprise 8 peak positions of 2 isolates; SLVs comprise 20 peak positions of 5 not related isolates; V. mimicus comprises 4 peak positions of one $V$. mimicus strain; Outlier comprises 4 peak positions of one outlier, in the second experiment for this isolate the maximal difference in peak positions was $52 \mathrm{Da}$.

$\operatorname{ctx} A B$ and tcp $A$ OmpU has a $58 \mathrm{Da}$ higher mass than the reference OmpU from N16961 (Table 4). The OmpU proteins from two closely related $V$. cholerae strains of serogroup O1, the "Classical" biotype, RC27 (presence of $c t x A B$ unknown, tcp $A+$ ) and $\mathrm{O} 395(\operatorname{ctx} A B+$ and $t c p A+)$, were identical to that of the O1 Hikojima strain tested in this study (FFIVC129), having three amino acid mutations compared to N16961 OmpU, which results in a mass difference of $1 \mathrm{Da}$ (Table 3). All other OmpU homologs retrieved in the BLASTp search contained ten or more mutations compared to the reference OmpU, resulting in a $58 \mathrm{Da}$ lower mass in one case (strain BJG-01) or $70 \mathrm{Da}$ or more difference in all other cases. The isolates harboring these OmpUs were all non-O1/O139 strains, with the exception of two O1 strains. However, no $c t x A B$ or $t c p A$ genes were found in the genome sequences of these strains, which strongly suggests that these are non-epidemic strains.

In addition to the screening of OmpU homologs present in the NCBI protein database, 149 omp $U$ sequences identified in completed whole genome sequences or whole genome shotgun (WGS) data of $V$. cholerae isolates available in the NCBI database were analyzed, and concomitantly, screened for the presence of the toxigenicity genes $\operatorname{ctx} A$ and $t c p A$. Based on sequence similarity with the $\mathrm{O}$-antigen biosynthesis genes of O1 and O139 in N16961 and MO45,

Table 2 MALDI-TOF MS data of selected biomarker peak (OmpU) of two genotype groups (GT1, toxigenic and epidemic V. cholerae 01/0139; GT2, non-toxigenic 01) obtained from two separate experiments

\begin{tabular}{|c|c|c|c|c|c|c|}
\hline & \multicolumn{6}{|c|}{$\mathrm{m} / \mathrm{z}$} \\
\hline & \multicolumn{3}{|c|}{ GT $1^{a}$} & \multicolumn{3}{|c|}{ GT 2} \\
\hline & Exp1 & Exp2 & $\Delta \operatorname{Exp} 1, \operatorname{Exp} 2$ & Exp1 & Exp2 & $\Delta \operatorname{Exp} 1, \operatorname{Exp} 2$ \\
\hline Mean & 34750 & 34565 & -185 & 34670 & 34495 & -175 \\
\hline Median & 34745 & 34565 & -180 & 34670 & 34490 & -180 \\
\hline Maximum $\Delta$ & 25 & 30 & & 15 & 30 & \\
\hline Minimum $\Delta$ & 35 & 50 & & 30 & 35 & \\
\hline
\end{tabular}

${ }^{\mathrm{a} O 1}$ Hikojima isolate not included. 


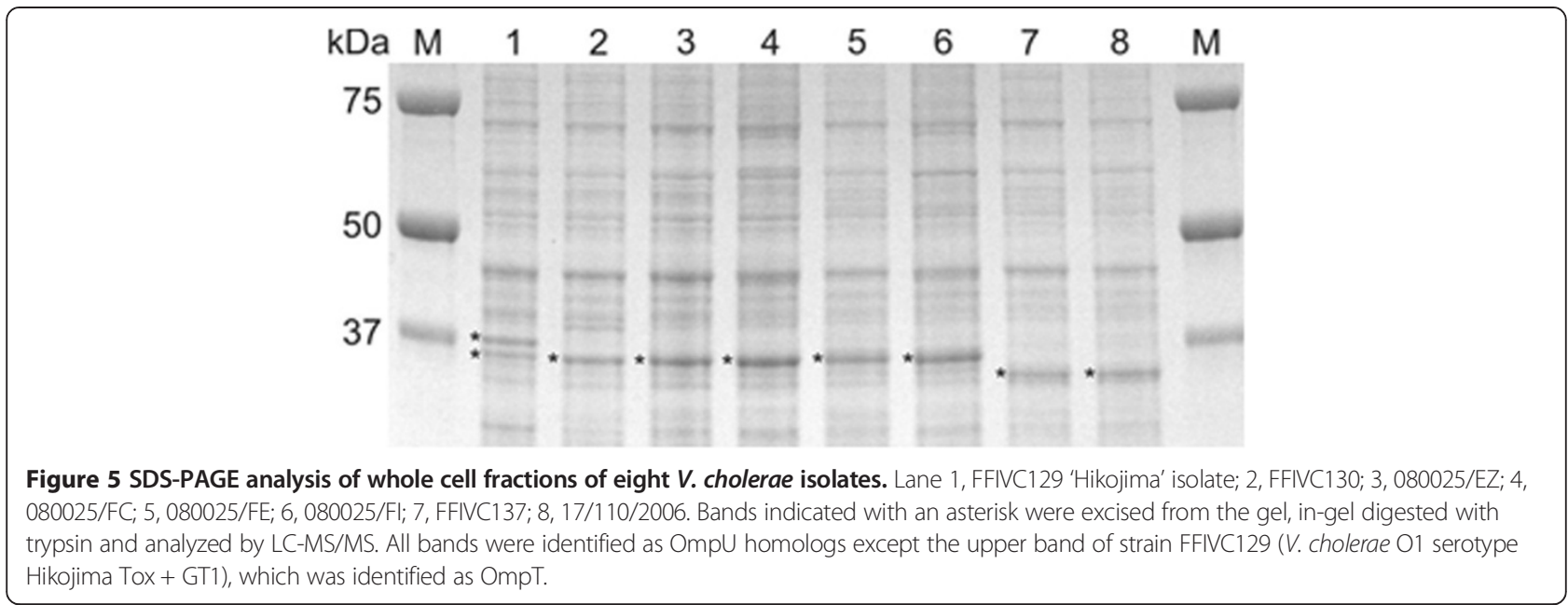

respectively, 108 strains were presumed O1 or O139. The amino acid sequence variation in $\mathrm{OmpU}$ in the 102 strains that also contained $\operatorname{ctx} A$ and $\operatorname{tcp} A$ was limited. In nine strains (including CP1038(11)) there was one amino acid difference compared to reference OmpU, resulting in 58 and $48 \mathrm{Da}$ higher mass for eight strains and one strain, respectively. The variation in OmpU from six serogroup $\mathrm{O} 1$ isolates not harboring
$\operatorname{ctxA}$ and tcpA differed $70 \mathrm{Da}$ or more, similar to what was found with the BLASTp search. From the 41 analyzed non-O1/O139 strains the OmpU mass was in one case (strain BJG-01) 58 Da lower than that of the reference OmpU (see also BLASTp search) and in all other cases differed more than $70 \mathrm{Da}$.

It was shown that OmpU homologs differing $72 \mathrm{Da}$ in theoretical mass (GT1 and GT2) could be well

Table 3 Theoretical and measured masses of OmpUs of $16 \mathrm{~V}$. cholerae isolates

\begin{tabular}{|c|c|c|c|c|c|c|c|}
\hline \multirow[t]{3}{*}{ Isolate } & \multirow[t]{3}{*}{ GT } & \multicolumn{2}{|c|}{ Theoretical } & \multicolumn{4}{|c|}{ Measured } \\
\hline & & \multirow[b]{2}{*}{$\operatorname{mass}^{a}$} & \multirow[b]{2}{*}{$\Delta^{\mathbf{b}}$} & \multicolumn{2}{|c|}{$1^{\text {st }} \exp$} & \multicolumn{2}{|c|}{$2^{\text {nd }} \exp$} \\
\hline & & & & mass $^{c}$ & $\Delta$ ref $^{\mathrm{d}}$ & mass $^{c}$ & $\Delta$ ref $^{\mathrm{d}}$ \\
\hline 080025/EZ & 1 & 34656 & 0 & 34755 & +6 & 34567 & +12 \\
\hline FFIVC130 & 1 & 34656 & 0 & 34742 & -6 & 34543 & -12 \\
\hline FFIVC129 & 1 & 34657 & +1 & N.D. ${ }^{e}$ & & N.D. ${ }^{e}$ & \\
\hline FFIVC114 & 4 & 35595 & +939 & 35683 & +934 & 35506 & -951 \\
\hline 080025/FE & 2 & 34584 & -72 & 34672 & -77 & 34482 & -73 \\
\hline 080025/FI & 2 & 34584 & -72 & 34678 & -71 & 34508 & -47 \\
\hline 080025/FL & 3 & 35566 & +910 & 35656 & +907 & 35469 & +914 \\
\hline $17 / 110 / 2006$ & 6 & 33871 & -785 & 33975 & -774 & 33733 & -822 \\
\hline $2 / 110 / 2006$ & 5 & 34961 & +305 & 35031 & +282 & 34875 & +320 \\
\hline 080025/FR & singleton & 34870 & +214 & 34951 & +203 & 34784 & +229 \\
\hline 080025/GE & 3 & 35566 & +910 & 35670 & +922 & 35501 & +946 \\
\hline FFIVC050 & singleton & 33840 & -816 & 33924 & -824 & 33748 & -807 \\
\hline FFIVC084 & singleton & 34811 & +155 & 34884 & +136 & 34683 & +128 \\
\hline FFIVC137 & singleton & 35709 & +1053 & 35813 & +1065 & N.D..$^{f}$ & \\
\hline 4/110/2006 & singleton & 34122 & -534 & 34198 & -550 & 33977 & -578 \\
\hline $14 / 110 / 2006$ & singleton & 34826 & +170 & N.D. ${ }^{f}$ & & 34716 & +161 \\
\hline
\end{tabular}

${ }^{\mathrm{a}}$ Theoretical mass of mature OmpU in Da.

${ }^{\mathrm{b}}$ Difference in mass with theoretical mass of OmpU of isolate 080025/EZ, in Da.

${ }^{\mathrm{C}}$ Mean of peak masses obtained from 4 different MALDI spots.

${ }^{\mathrm{d}}$ The average of OmpU peak masses of strain 080025/EZ and FFIVC130 was set as reference.

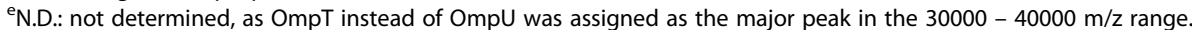

${ }^{f}$ N.D.: not determined because of failed measurement. 
Table 4 Results of BLASTp search using OmpU of Vibrio cholerae 01 El Tor N16961 (calculated molecular mass $34655.65 \mathrm{Da}$ ) as query sequence

\begin{tabular}{|c|c|c|c|c|c|c|c|c|c|c|c|}
\hline Hit nr. & $\begin{array}{l}\text { Mutations } \\
\text { compared to } \\
\text { OmpU N16961 }\end{array}$ & $\begin{array}{l}\text { Theoretical } \\
\text { mass }(\mathrm{Da})\end{array}$ & Strain & Serogroup & Serotype & Biotype & Origin & $\begin{array}{l}\text { Year of } \\
\text { isolation }\end{array}$ & $\operatorname{ctx} B^{a}$ & $\operatorname{tcp} A^{a}$ & $\begin{array}{c}\text { Epidemic (E) or } \\
\text { non-epidemic } \\
\text { strain }(\mathrm{N})\end{array}$ \\
\hline 1 & & 34656 & N16961 & 01 & Inaba & El tor & Bangladesh & 1975 & ctxAB+ & tcpA+ & $E$ \\
\hline 1 & & 34656 & CP1032 (5) & 01 & Ogawa & El tor & Mexico & 1991 & $\mathrm{ct} \times \mathrm{AB}+$ & tcpA+ & E \\
\hline 1 & & 34656 & CP1044 (17) & $\mathrm{O} 1^{\mathrm{c}}$ & & & Peru & 1991 & $\mathrm{ct} \times \mathrm{AB}+$ & tcpA+ & E \\
\hline 1 & & 34656 & $4260 B$ & 0139 & & & Bangladesh & 1993 & $\mathrm{ctxAB+}$ & tcpA+ & E \\
\hline 1 & & 34656 & CP1046 (19) & $\mathrm{O} 1^{\mathrm{c}}$ & & & Peru & 1995 & $\begin{array}{l}\mathrm{ctxA} A \\
\operatorname{ctxB}^{f}\end{array}$ & tcpA+ & E \\
\hline 1 & & 34656 & CP1047 (20) & $\mathrm{O} 1^{\mathrm{c}}$ & & & Peru & 1995 & $\mathrm{ct} \times \mathrm{AB}+$ & $\mathrm{tcpA}+$ & $E$ \\
\hline 1 & & 34656 & CP1033 (6) & $\mathrm{O} 1^{\mathrm{c}}$ & & & Mexico & 2000 & $\mathrm{ctxAB+}$ & tcpA+ & E \\
\hline 1 & & 34656 & CIRS101 & 01 & Inaba & El tor & Bangladesh & 2002 & $\mathrm{ctXAB+}$ & tcpA+ & E \\
\hline 1 & & 34656 & CP1037 (10) & 01 & & & Mexico & 2003 & $\begin{array}{l}\operatorname{ctx} A+ \\
\operatorname{ctxB}^{-}\end{array}$ & truncated & E \\
\hline 1 & & 34656 & CP1040 (13) & $\mathrm{O} 1^{c}$ & & & Zambia & 2004 & $\mathrm{ct} \times A B+$ & tcpA+ & E \\
\hline 1 & & 34656 & CP1041 (14) & 01 & Ogawa & El tor & Zambia & 2004 & $\mathrm{ct} \times \mathrm{AB}+$ & tcpA+ & E \\
\hline 1 & & 34656 & CP1030 (3) & $\mathrm{O} 1^{\mathrm{c}}$ & & & Mexico & 2008 & $\mathrm{ct} \times \mathrm{AB}+$ & tcpA+ & E \\
\hline 1 & & 34656 & $\mathrm{HC}-06 \mathrm{~A} 1^{\mathrm{e}}$ & $\mathrm{O} 1$ & Ogawa & El tor & Haiti & 2010 & $\operatorname{ctxAB+}$ & $\mathrm{tcpA}+$ & $E$ \\
\hline 1 & & 34656 & CP1042 (15) & O1 & Ogawa & El tor & Thailand & 2010 & $\mathrm{ct} \times A B+$ & tcpA+ & E \\
\hline 1 & & 34656 & CP1048 (21) & 01 & Ogawa & El tor & Bangladesh & 2010 & $\mathrm{ct} \times \mathrm{AB}+$ & tcpA+ & E \\
\hline 1 & & 34656 & CP1050 (23) & $\mathrm{O} 1^{\mathrm{c}}$ & & & Bangladesh & 2010 & $\operatorname{ctx} A B+$ & tcpA+ & E \\
\hline $2^{b}$ & & 34656 & M66-2 & $\mathrm{O} 1$ & - & - & Indonesia & 1937 & $\begin{array}{l}\operatorname{ctx} A+ \\
\operatorname{ctxB}{ }^{-}\end{array}$ & tcpA+ & E \\
\hline 2 & & 34656 & MAK 757 & 01 & Ogawa & El Tor & Indonesia & 1937 & $\mathrm{ct} \times A B+$ & tcpA+ & E \\
\hline 2 & & 34656 & V52 & $\mathrm{O} 37$ & & & Sudan & 1968 & $\mathrm{ct} \times A B+$ & tcpA+ & E \\
\hline 2 & & 34656 & RC9 & 01 & Ogawa & El Tor & Kenya & 1985 & $\mathrm{ctXAB+}$ & tcpA+ & E \\
\hline 2 & & 34656 & BX 330286 & 01 & Inaba & El Tor & Australia & 1986 & $\mathrm{ct} \times \mathrm{AB}+$ & tcpA+ & E \\
\hline 2 & & 34656 & M010 & 0139 & & & India & 1992 & $\mathrm{ct} \times \mathrm{AB}+$ & tcpA+ & E \\
\hline 2 & & 34656 & MJ-1236 & 01 & Inaba & El Tor & Bangladesh & 1994 & $\mathrm{ctxAB+}$ & tcpA+ & E \\
\hline 2 & & 34656 & B33 & 01 & Ogawa & El Tor & Mozambique & 2004 & $\mathrm{ctxAB+}$ & tcpA+ & E \\
\hline 3 & F287I & 34622 & unknown & unknown & & El tor & & & unknown & unknown & unknown \\
\hline 4 & G325D & 34714 & CP1038 (11) & 01 & Ogawa & El tor & Zimbabwe & 2003 & $\operatorname{ctx} A B+$ & tcpA+ & E \\
\hline 5 & $\begin{array}{l}\text { E290K, V324A, } \\
325 \mathrm{~S}\end{array}$ & 34657 & $\mathrm{RC} 27$ & O1 & & Classical & Indonesia & 1991 & truncated & truncated & $\mathrm{N}$ \\
\hline 5 & $\begin{array}{l}\text { E290K, V324A, } \\
325 \mathrm{~S}\end{array}$ & 34657 & O395 & 01 & Ogawa & Classical & India & 1965 & $\mathrm{ctxAB+}$ & truncated & N \\
\hline 7 & 10 mut & 34598 & BJG-01 & non-O $1^{d}$ & & & & & $\begin{array}{l}\operatorname{ctxA} A, \\
\operatorname{ctxB}^{-}\end{array}$ & unknown & N \\
\hline 8 & 9 del , 13 mut & 33840 & $\mathrm{HE}-25$ & non-O1 ${ }^{d}$ & & & Haiti & 2010 & $\operatorname{ctxAB}-$ & $\operatorname{tcpA}$ - & $\mathrm{N}$ \\
\hline 9 & 9 del, 13 mut & 33840 & AM-19226 & O39 & & & Bangladesh & 2001 & $\mathrm{ctxAB}-$ & tcpA - & $\mathrm{N}$ \\
\hline 10 & 7 del, 18 mut & 33911 & RC385 & 0135 & & & USA & 1998 & $c t \times A B-$ & tcpA - & N \\
\hline
\end{tabular}

${ }^{a} c t x A B$ and $\operatorname{tcp} A$ genes were identified by blastx search of whole genome sequences using $\operatorname{ct} x A B$ and tcpA of strain $\mathrm{N} 16961$ as query sequences.

${ }^{b}$ Hit nr. 2 represents OmpU identical to hit nr. 1 except for nine additional $\mathrm{N}$-terminal residues resulting from a wrongly identified translation start.

'Presumed serotype $\mathrm{O} 1$ based on sequence similarity with O-antigen biosynthesis genes VC0241 to VC0244A from N16961.

dPresumed serotype non-O1/O139, based on lack of sequence similarity with O-antigen biosynthesis genes VC0241 to VC0244A from N16961 and O139. Accession: AB012956 bp 22084-24660 wbfH/wbfl/wbfJ).

'This strain represents also 44 other Vibrio cholerae $\mathrm{O} 1 \mathrm{El}$ Tor Ogawa isolates from same outbreak with identical OmpU sequence and toxigenicity genes.

${ }^{\mathrm{f}} \mathrm{No}$ ctxB similar to $\operatorname{ct} \times B$ of N16961 (locus_tag;VC1456). Presence of another variant of $c t \times B$ cannot be excluded. 
distinguished, as well as $\mathrm{OmpU}$ proteins from 080025/FL, 080025/GE (GT3) and FFIVC114 (GT4), which differed by only $29 \mathrm{Da}$ in mass (GT3 (080025/FL, 080025/GE) and GT4 (FFIVC114)). Therefore, it can be assumed that OmpUs from epidemic strains (34,656 Da to $34,714 \mathrm{Da})$ can be distinguished from non-epidemic $V$. cholerae strains (less than $34,598 \mathrm{Da}$ or more than $34,734 \mathrm{Da}$ ).

\section{Discussion}

In this study, we demonstrate that the outer membrane protein OmpU from $V$. cholerae can be used as a biomarker of epidemic strains of $V$. cholerae in a new adapted MALDI-TOF MS assay. The use of ferulic acid as a matrix instead of $\alpha$-cyano-4-hydroxycinnamic acid, commonly used in standardized MALDI-TOF assays for identification of bacteria, allowed for a larger measurable mass range $(4-80 \mathrm{kDa})$, thereby including larger proteins such as $\mathrm{OmpU}(34 \mathrm{kDa})$ in the analysis. The resolution of the spectra was sufficient to discriminate between epidemic $V$. cholerae $\mathrm{O} 1 / \mathrm{O} 139$ strains and other less pathogenic strains on the basis of mass differences in OmpU. OmpU appeared to be the dominant peak in an $m / z$ range of $30,000-40,000$ in the spectra of all 48 tested strains except for the spectrum representing the $V$. cholerae O1 strain of serotype Hikojima, where the most dominant peak was identified as OmpT. $\mathrm{OmpU}$ and $\mathrm{OmpT}$ are major outer membrane proteins of $V$. cholerae [25]. OmpU is expressed when cells are colonizing a human host, while OmpT is repressed at this time [26]. Reproducible differences between the OmpU peak masses of different MLST genotypes ranging from 32.4 to $35.7 \mathrm{kDa}$ enabled discrimination of epidemic isolates from less or non-pathogenic isolates. Sequencing of the ompU genes in $V$. cholerae isolates representing different genotypes and a database analysis revealed that the amino acid sequence of OmpU from the epidemic $V$. cholerae $\mathrm{O} 1 / \mathrm{O} 139$ and $\mathrm{O} 37$ strains is highly conserved, while OmpU homologs from other $V$. cholerae isolates varied from this sequence. These differences in amino acid sequence resulted in almost all cases in mass differences of more than $70 \mathrm{Da}$, which was sufficient to distinguish the "epidemic" OmpU proteins from OmpU proteins of other strains with the resolution of the method presented here. In general, differences in OmpU peak masses between strains were well reproducible in multiple experiments. However, small variations in the OmpU peak masses between separate experiments were observed, indicating that the method requires inclusion of a standard sample for calibration containing a characterized $V$. cholerae strain. Among the OmpU homologs of non-epidemic strains present in the NCBI database, one had a theoretical mass of $58 \mathrm{Da}$ less than that of the "epidemic" OmpU protein, while in all other non-epidemic $V$. cholerae isolates the mass differed more than $70 \mathrm{Da}$. From the in silico analyzed 102 'epidemic' isolates the theoretical mass of OmpU from eight, one and two isolates differed 58, 48 and $1 \mathrm{Da}$, respectively. Therefore, it can be assumed that epidemic strains (34,656 Da to $34,714 \mathrm{Da}$ ) can be distinguished from non-epidemic $V$. cholerae strains (less than $34,598 \mathrm{Da}$ or more than $34,734 \mathrm{Da}$ ) based on OmpU using the described MALDI-TOF MS assay.

The $V$. cholerae strain of serotype Hikojima was shown to produce both OmpU and OmpT (Figure 5). However, in the obtained MS-spectra OmpU was not detected well and therefore its peak mass was not determined. More isolates of the Hikojima serotype, which is a rare serotype, need to be tested to determine whether this result is strain or serotype specific [23]. The theoretical mass of OmpU of the tested strain is only one Da less than that of the N16961 OmpU.

It should be noted that not all strains of serogroup O1 are toxigenic. Some strains are not able to produce the cholera toxin because these isolates lack the $\operatorname{ctx} A B$ and tcp $A$ genes necessary for full virulence of $V$. cholerae $[21,27]$. Furthermore, the non-toxigenic $\mathrm{O} 1$ isolates in this study were also genetically distinct from the epidemic $V$. cholerae $\mathrm{O} 1 / \mathrm{O} 139$ cluster (GT1), indicating that other unknown virulence factors could be present in the epidemic $V$. cholerae $\mathrm{O} 1 / \mathrm{O} 139$ cluster that are absent in non-toxigenic $V$. cholerae $\mathrm{O} 1$ isolates. Previous studies have shown the presence of non-toxigenic $V$. cholerae $\mathrm{O} 1$ strains in the environment and in humans $[6,18,21,27]$. Serotyping is therefore not a reliable method for the identification of toxigenic and epidemic $V$. cholerae $\mathrm{O} 1 / \mathrm{O} 139$ strains. Furthermore, $V$. cholerae non-O1/ O139 isolates have been described that are able to produce the cholera toxin but are not considered epidemic because only strains of serogroup O1/O139 and O37 are able to cause large outbreaks $[6,21,27]$. Thus, the presence of the $\operatorname{ctx} A B$ and $t c p A$ genes is not the only prerequisite for epidemic potential.

We have found that OmpU from epidemic V. cholerae has a unique and conserved amino acid sequence, which not only can be used in the presented MALDI-TOF MS assay, but also in a targeted PCR method. The difference in OmpU sequences between epidemic and non-epidemic isolates as well as the sequence variation among nonepidemic strains raises the question of whether this variation is due to genetic drift or specific adaptation to different niches. From a DNA alignment of a 5,000 bp region surrounding the ompU gene of seven epidemic $\mathrm{O} 1$ and five non-toxigenic strains (Additional file 2: Figure S2), it became clear that the ompU gene has undergone a higher mutation rate compared to the surrounding genes and intergenic regions. This suggests that OmpU has been subject to selective pressure, possibly as a result of adaptation to particular niches. A role for 
OmpU in host colonization has been proposed, potentially in enhancing attachment to epithelia in the gut or conferring resistance to bile, ionic detergents and organic acids [28-31]. Based on a three-dimensional model of $V$. cholerae $\mathrm{OmpU}$, most of the variable regions are located in regions exposed to the outside of the cell (not shown), which supports a host-dependent variation hypothesis.

\section{Conclusions}

Each year more than half a million people develop cholera. To reduce the burden of this devastating disease, new strategies must be developed. By minimizing the spread of the pathogen, the disease incidence can be reduced. To control a cholera outbreak, quick identification at the start of a potential outbreak and rapid discrimination between epidemic $V$. cholerae and other $V$. cholerae isolates could be helpful in introducing effective hygienic measurements [32,33]. To this point, discrimination between the toxigenic and epidemic $V$. cholerae strains and the non-pathogenic or less pathogenic strains has required multiple tests. The deviation in amino acid sequences of $\mathrm{OmpU}$ homologs of non-epidemic strains from those of the OmpU protein of strain N16961, which is conserved among almost all epidemic strains, makes OmpU an important biomarker to discriminate between epidemic $V$. cholerae $\mathrm{O} 1 / \mathrm{O} 139$ and other $V$. cholerae isolates. The mass differences of OmpU proteins resulting from this sequence variation together with the high abundance of this protein in bacteria allows for the use of MALDI-TOF MS analysis as a rapid and discriminatory method for identifying epidemic strains of $V$. cholerae. Based on the described classification technique, one would maximally generate only one false negative classification when all characterized and sequenced $V$. cholerae isolates are screened with the developed MALDI-TOF MS assay.

\section{Additional files}

Additional file 1: Figure S1. Alignment of OmpU sequences. The ompU genes from 16 isolates were sequenced. The translated OmpU amino acid sequences and the OmpU sequence of $\mathrm{O} 1 \mathrm{El}$ Tor strain N16961 were aligned using ClustalW software.

Additional file 2: Figure S2. Alignment of $5 \mathrm{kbp}$ DNA fragments of omp $U$ loci from five non-toxigenic strains (1-6) and seven toxigenic 01 strains (7-13). Black vertical lines and regions indicate non-conserved bases. The upper green bar indicates conservation in the consensus. The diagram was made using Geneious software. $r r m J$, 235 rRNA methyltransferase J; greA, transcription elongation factor GreA; ompU, outer membrane protein OmpU; dacB, D-alanyl-D-alanine carboxypeptidase/endopeptidase; tyrS-2, tyrosyl-tRNA synthetase.

\section{Authors' contributions}

Conceived and designed the experiments: AP HT, JAMK, ET. Performed the experiments: AP, HT, MN, RS, JMEH, RHMG, ALJ, JSO. Analyzed the data: AP, $H T$, ET. Contributed reagents/materials/analysis tools: AP, MN, RS, JSO, ET. Wrote the paper: AP, HT, MN, RK, JAMK, JSO, ET. Contributed to hypothesis generation and overall study design: AP, HT, JAMK, ET. All authors read and approved the final manuscript.

\section{Acknowledgements}

This work was financially supported by the Dutch Ministry of Defense, grant number V1036. This work was part of the European Defence Agency (EDA) project B0060 involving biodefence institutions from Spain, Poland, Norway and The Netherlands.

\section{Author details}

${ }^{1}$ Department of CBRN Protection, TNO, P.O. Box 45, Rijswijk 2280 AA, The Netherlands. ${ }^{2}$ Military Institute of Hygiene and Epidemiology, 24-100 Pulawy, Lubelska 2, Poland. ${ }^{3}$ Instituto Tecnológico La Marañosa, Spanish Ministry of Defence, San Martín de la Vega, Madrid, Spain. ${ }^{4}$ Radiological Environmental Recovery Program, Department of Environment, Centro de Investigaciones Energ eticas, Medioambientales y Tecnologicas (CIEMAT, Madrid, Spain. ${ }^{5}$ Norwegian Defence Research Establishment, P. O. Box 25, Kjeller N-2027, Norway.

Received: 12 December 2013 Accepted: 10 June 2014 Published: 18 June 2014

\section{References}

1. Anonymous World Health Organsization (WHO): Fact Sheet No. 107, Cholera, WHO Media centre [online]. 2012 http://www.who.int/ mediacentre/factsheets/fs107/en/.

2. Harris JB, LaRocque RC, Qadri F, Ryan ET, Calderwood SB: Cholera. Lancet 2012, 379(9835):2466-2476.

3. Anonymous Centers for Disease Control and Prevention (CDC): Category a list, centers for disease control and prevention, Atlanta, GA. [online]. 2012 http://www.bt.cdc.gov/agent/agentlist-category.asp.

4. Cho YJ, Yi H, Lee JH, Kim DW, Chun J: Genomic evolution of Vibrio cholerae. Curr Opin Microbiol 2010, 13(5):646-651.

5. Crump JA, Bopp CA, Greene KD, Kubota KA, Middendorf RL, Wells JG, Mintz ED: Toxigenic Vibrio cholerae serogroup 0141-associated cholera-like diarrhea and bloodstream infection in the United States. J Infect Dis 2003, 187(5):866-868.

6. Faruque SM, Chowdhury N, Kamruzzaman M, Dziejman M, Rahman MH, Sack DA, Nair GB, Mekalanos JJ: Genetic diversity and virulence potential of environmental Vibrio cholerae population in a cholera-endemic area. Proc Natl Acad Sci U S A 2004, 101(7):2123-2128.

7. Seng P, Drancourt M, Gouriet F, La Scola B, Fournier PE, Rolain JM, Raoult D: Ongoing revolution in bacteriology: routine identification of bacteria by matrix-assisted laser desorption ionization time-of-flight mass spectrometry. Clin Infect Dis 2009, 49(4):543-551.

8. Cherkaoui A, Hibbs J, Emonet S, Tangomo M, Girard M, Francois P, Schrenzel J: Comparison of two matrix-assisted laser desorption ionization-time of flight mass spectrometry methods with conventional phenotypic identification for routine identification of bacteria to the species level. J Clin Microbiol 2010, 48(4):1169-1175.

9. Mellmann A, Bimet F, Bizet C, Borovskaya AD, Drake RR, Eigner U, Fahr AM, He Y, llina EN, Kostrzewa M, Maier T, Mancinelli L, Moussaoui W, Prevost G, Putignani L, Seachord CL, Tang YW, Harmsen D: High interlaboratory reproducibility of matrix-assisted laser desorption ionization-time of flight mass spectrometry-based species identification of nonfermenting bacteria. J Clin Microbiol 2009, 47(11):3732-3734.

10. van Veen SQ, Claas EC, Kuijper EJ: High-throughput identification of bacteria and yeast by matrix-assisted laser desorption ionization-time of flight mass spectrometry in conventional medical microbiology laboratories. J Clin Microbiol 2010, 48(3):900-907.

11. Lista F, Reubsaet FA, De Santis R, Parchen RR, de Jong AL, Kieboom J, van der Laaken AL, Voskamp-Visser IA, Fillo S, Jansen HJ, Van der Plas J, Paauw A: Reliable identification at the species level of Brucella isolates with MALDI-TOF-MS. BMC Microbio/ 2011, 11(1):267.

12. Lasch P, Beyer W, Nattermann H, Stammler M, Siegbrecht E, Grunow R, Naumann D: Identification of Bacillus anthracis by using matrix-assisted 
laser desorption ionization-time of flight mass spectrometry and artificial neural networks. Appl Environ Microbiol 2009, 75(22):7229-7242.

13. Seibold E, Maier T, Kostrzewa M, Zeman E, Splettstoesser W: Identification of Francisella tularensis by whole-cell matrix-assisted laser desorption ionization-time of flight mass spectrometry: fast, reliable, robust, and cost-effective differentiation on species and subspecies levels. J Clin Microbiol 2010, 48(4):1061-1069.

14. Vanlaere E, Sergeant K, Dawyndt P, Kallow W, Erhard M, Sutton H, Dare D, Devreese B, Samyn B, Vandamme P: Matrix-assisted laser desorption ionisation-time-of-flight mass spectrometry of intact cells allows rapid identification of Burkholderia cepacia complex. J Microbiol Methods 2008, 75(2):279-286

15. Karger A, Stock R, Ziller M, Elschner MC, Bettin B, Melzer F, Maier T, Kostrzewa M, Scholz HC, Neubauer H, Tomaso H: Rapid identification of Burkholderia mallei and Burkholderia pseudomallei by intact cell Matrixassisted Laser Desorption/lonisation mass spectrometric typing. BMC Microbiol 2012, 12:229-2180-12-229.

16. Madonna AJ, Basile F, Ferrer I, Meetani MA, Rees JC, Voorhees KJ: On-probe sample pretreatment for the detection of proteins above $15 \mathrm{KDa}$ from whole cell bacteria by matrix-assisted laser desorption/ionization timeof-flight mass spectrometry. Rapid Commun Mass Spectrom 2000, 14(23):2220-2229.

17. Meetani MA, Voorhees KJ: MALDI mass spectrometry analysis of high molecular weight proteins from whole bacterial cells: pretreatment of samples with surfactants. J Am Soc Mass Spectrom 2005, 16(9):1422-1426.

18. Sellek RE, Niemcewicz M, Olsen JS, Bassy O, Lorenzo P, Marti L, Roszkowiak A, Kocik J, Cabria JC: Phenotypic and genetic analyses of 111 clinical and environmental 01, 0139, and non-01/0139 Vibrio cholerae strains from different geographical areas. Epidemiol Infect 2012, 140(8):1389-1399.

19. Usera MA, Echeita A, Olsvik O, Evins GM, Cameron DN, Popovic T: Molecular subtyping of Vibrio cholerae 01 strains recently isolated from patient, food and environmental samples in Spain. Eur I Clin Microbiol Infect Dis 1994, 13(4):299-303.

20. Olsen JS, Aarskaug T, Skogan G, Fykse EM, Ellingsen AB, Blatny JM: Evaluation of a highly discriminating multiplex multi-locus variablenumber of tandem-repeats (MLVA) analysis for Vibrio cholerae. J Microbiol Methods 2009, 78(3):271-285.

21. Teh CS, Chua KH, Thong KL: Genetic variation analysis of Vibrio cholerae using multilocus sequencing typing and multi-virulence locus sequencing typing. Infect Genet Evol 2011, 11(5):1121-1128.

22. Cleveland DW, Fischer SG, Kirschner MW, Laemmli UK: Peptide mapping by limited proteolysis in sodium dodecyl sulfate and analysis by gel electrophoresis. J Biol Chem 1977, 252(3):1102-1106.

23. Finkelstrein RA: Chapter 24 Cholerae, Vibrio cholerae 01 and 0139, and other Pathogenic Vibrios. In Medical Microbiology. 4th edition. Edited by Baron S. Galveston: Galveston (TX): University of Texas Medical Branch; 1996. http://www.ncbi.nlm.nih.gov/books/NBK8407/.

24. O'Shea YA, Reen FJ, Quirke AM, Boyd EF: Evolutionary genetic analysis of the emergence of epidemic Vibrio cholerae isolates on the basis of comparative nucleotide sequence analysis and multilocus virulence gene profiles. J Clin Microbiol 2004, 42(10):4657-4671.

25. Simonet VC, Basle A, Klose KE, Delcour AH: The Vibrio cholerae porins OmpU and OmpT have distinct channel properties. J Biol Chem 2003, 278(19):17539-17545.

26. Crawford JA, Kaper JB, DiRita VJ: Analysis of ToxR-dependent transcription activation of ompU, the gene encoding a major envelope protein in Vibrio cholerae. Mol Microbiol 1998, 29(1):235-246.

27. Pang B, Yan M, Cui Z, Ye X, Diao B, Ren Y, Gao S, Zhang L, Kan B: Genetic diversity of toxigenic and nontoxigenic Vibrio cholerae serogroups 01 and 0139 revealed by array-based comparative genomic hybridization. J Bacteriol 2007, 189(13):4837-4849.

28. Provenzano D, Lauriano CM, Klose KE: Characterization of the role of the ToxR-modulated outer membrane porins $\mathrm{OmpU}$ and OmpT in Vibrio cholerae virulence. J Bacteriol 2001, 183(12):3652-3662.

29. Merrell DS, Bailey C, Kaper JB, Camilli A: The ToxR-mediated organic acid tolerance response of Vibrio cholerae requires OmpU. J Bacteriol 2001, 183(9):2746-2754.

30. Sperandio V, Giron JA, Silveira WD, Kaper JB: The OmpU outer membrane protein, a potential adherence factor of Vibrio cholerae. Infect Immun 1995, 63(11):4433-4438.
31. Bari W, Lee KM, Yoon SS: Structural and functional importance of outer membrane proteins in Vibrio cholerae flagellum. J Microbiol 2012, 50(4):631-637

32. Dick MH, Guillerm M, Moussy F, Chaignat CL: Review of two decades of cholera diagnostics-how far have we really come? PLOS Negl Trop Dis 2012, 6(10):e1845.

33. Greenhill A, Rosewell A, Kas M, Latorre L, Sibaa P, Horwooda P: Improved laboratory capacity is required to respond better to future cholera outbreaks in Papua New Guinea. Western Pac Surveill Response J 2012, 3(2):30-32. doi:10.5365/wpsar.2011.2.4.016. WPSAR 2012, 3(2):30.

doi:10.1186/1471-2180-14-158

Cite this article as: Paauw et al:: $\mathrm{OmpU}$ as a biomarker for rapid discrimination between toxigenic and epidemic Vibrio cholerae 01/ 0139 and non-epidemic Vibrio cholerae in a modified MALDI-TOF MS assay. BMC Microbiology 2014 14:158.

\section{Submit your next manuscript to BioMed Central and take full advantage of:}

- Convenient online submission

- Thorough peer review

- No space constraints or color figure charges

- Immediate publication on acceptance

- Inclusion in PubMed, CAS, Scopus and Google Scholar

- Research which is freely available for redistribution

Submit your manuscript at www.biomedcentral.com/submit 